\title{
Associations for preschool environmental quality with outdoor time and moderate-to-vigorous physical activity in Norwegian preschools
}

\author{
Kjersti Johannessen, ${ }^{1 \star}$ Elisabeth Bjørnestad ${ }^{2}$ Ada Kristine \\ Ofrim Nilsen, ${ }^{1}$ Einar Ylvisåker, ${ }^{1}$ Merete Nornes-Nymark, ${ }^{1}$ \\ Mari Engsæter, ${ }^{1}$ Lillian Pedersen ${ }^{1} \&$ Eivind Aadland ${ }^{1}$ \\ ${ }^{1}$ Western Norway University of Applied Science; ${ }^{2}$ Oslo Metropolitan University
}

\begin{abstract}
Various aspects of the preschool environment may either promote or restrict children's moderateto-vigorous physical activity (MVPA), for example through opportunities for outdoor play. The aim of the present study was to determine associations for preschool environmental quality with outdoor time and MVPA in preschoolers. In total, 358 Norwegian 2-6-year-old children had 1-3 valid 14-day periods of accelerometer-determined MVPA (ActiGraph GT3X+) and corresponding logs of preschool outdoor time collected during 2015-2016. The children were enrolled in 30 different preschool departments for which we assessed environmental quality using the Early Childhood Environment Rating Scale-Revised (ECERS-R). Associations for preschool quality with outdoor time and MVPA were determined using multivariate pattern analysis. We found strong inverse associations between preschool quality and outdoor time (51.4\% explained variance), and weak inverse associations between preschool quality and MVPA (5.4\% explained variance). Associations were strongest for the "Space and Furnishings", "Personal Care Routines", "Language-Reasoning", and "Interaction" subscales of ECERS-R, in particular for aspects of safety practices. Children enrolled in departments rated as high quality spent less time outdoors and less time in MVPA. Thus, recognized quality aspects of preschool environments, in particular safety practices, might restrict children's movement opportunities.
\end{abstract}

Keywords: Preschool; kindergarten; physical activity; outdoor play; environmental characteristics; quality assessment

Received: June, 2020; Accepted: October, 2020; Published: December, 2020

\footnotetext{
^Correspondence: Kjersti Johannessen, e-mail: kjerstij@hvl.no

(C) 2020 K. Johannessen, E. Bjørnestad, A. K. O. Nilsen, E. Ylvisåker, M. Nornes-Nymark, M. Engsæter, L. Pedersen, \& E. Aadland. This is an Open Access article distributed under the terms of the Creative Commons Attribution 4.0 International License (https://creativecommons.org/licenses/by-nc/4.0/), allowing third parties to copy and redistribute the material in any medium or format and to remix, transform, and build upon the material for any purpose, even commercially, provided the original work is properly cited and states its license.

Citation: K. Fohannessen, E. Bjørnestad, A. K. O. Nilsen, E. Ylvisåker, M. Nornes-Nymark, M. Engsceter, L. Pedersen, E E. Aadland. "Associations for preschool environmental quality with outdoor time and moderate-to-vigorous physical activity in Norwegian preschools». Fournal for Research in Arts and Sports Education, Special Issue: Fysisk aktivitet, kropp og bevegelse i barnehagen, Vol. 4(2), 2020, pp. 7-25. http://dx.doi.org/10.23865/jased.v4.2485
} 


\section{K. Fohannessen et al.}

\section{Introduction}

Physical activity (PA) is important for health and development during early childhood and across the life span (Ahn \& Fedewa, 2011; Andersen et al., 2006; Carson et al., 2017; Timmons et al., 2012). In children, PA has been shown to be positively associated with academic achievements, psychosocial health, motor development, cardiometabolic health indicators, and decreased adiposity (Brewer, 2018; Carson et al., 2017; Timmons et al., 2012). Since PA levels have been shown to track from childhood into adulthood (Bingham et al., 2016), and because PA levels are known to decrease by age in school-aged children and adolescents (Cooper et al., 2015), it is important to establish healthy PA behaviors early in life (Malina, 2001).

Children under the age of six spend large amounts of time in Early Childhood Education and Care (ECEC) services in many countries. As social and physical environments have a strong influence on child behaviour and development (Brown et al., 2009), ECEC services have a critical role in providing opportunities for children to be physically active (Tonge et al., 2016).

The World Health Organization (WHO) recommends that children engage in $\geq 60$ minutes of moderate-to-vigorous PA (MVPA) every day (WHO, 2019), which is also the recommended level in the Nordic countries, including Norway (Tetens et al., 2012). This activity should be varied and developmentally appropriate to promote enjoyment and engagement among children. Consistent with the guidelines, The Norwegian Framework plan for Kindergartens (The Norwegian Directorate for Education and Training, 2017) recommends that preschools promote children's development of motor skills and physical capabilities. However, there is a growing concern regarding young children's PA levels (Das \& Horton, 2016; Truelove et al., 2018), as research shows both insufficient levels of MVPA and high levels of sedentary time in early childhood (Bornstein et al., 2011). A large Norwegian study recently found that only $55 \%$ of preschoolers (3-5 years) achieved the guideline amount of MVPA (Nilsen et al., 2019). Importantly, because Norwegian children spend a major proportion of their waking time in preschool (mean of 33 hours/week), this arena is highly relevant for their opportunities to be physically active. In fact, Nilsen et al. (2019) found that children accumulated $77 \%$ of their MVPA on weekdays during preschool hours. This finding, in addition to high preschool attendance rates in Norway (97\%) (SN, 2017) and most European countries (European Commission, 2009), place preschools as crucial arenas for promotion of PA.

Several studies have shown substantial variation in PA across preschools (Finn et al., 2002; Hesketh et al., 2017; Hinkley et al., 2012; Trost et al., 2010). Many factors might explain this variation, for example time schedules, policies and practices, teacher characteristics, group size, available play equipment, and other aspects of the physical environment (Dowda et al., 2004; Goldfield et al., 2012; Hinkley et 
al., 2016; Tonge et al., 2016; Vanderloo et al., 2015). Important and overarching factors might be the preschool's policy and understanding of quality of the service, and specifically, how teachers see their mandate to promote different aspects of child development.

The term quality in ECEC services describe the structural (teacher/child ratio, group size, teacher education and training, and teacher wages and benefits) and process (interactions among children, adults, and the environment) features of the environment that promote learning and development (Burchinal, 2018). If PA is considered an integrated part of the preschool curriculum to promote children's physical, mental, socio-emotional, and learning outcomes, PA will likely be promoted in the preschool setting. On the contrary, this might not be the case if teachers view PA as a factor that detract attention from other and more important parts of the curriculum. The teachers' view on PA might also affect time spent outdoors versus indoors, depending on priorities related to promotion of curricular activities versus recess. It is well known that preschoolers have higher PA levels when being outdoors versus indoors (Bingham et al., 2016). Furthermore, time spent outdoors during the preschool years has been shown to predict cognitive skills and selfregulation in school (Ulset et al., 2017). Thus, both PA and outdoor time is favorably related to child development, and spending more time outdoors is an effective way of promoting PA.

Research has demonstrated associations between various aspects of preschool quality and improved social and academic outcomes in young children (Belsky et al., 2007; Mashburn et al., 2008). The Early Childhood Environment Rating Scale Revised (ECERS - R) (Harms et al., 2005) is one of the most used observational tools for assessing preschool quality, including measurements of physical space, groupings, materials, instruction, health, and safety. However, despite the increasing focus on preschool quality, there is little research on quality in relation to PA behaviors. This relationship is relevant as PA is an important factor for child development, and as such an important factor to address when evaluating overall quality, though less focused in the ECERS-R instrument. Importantly, Dowda et al. (2009) found a positive relationship between objectively measured PA of 3-5-year-olds and service quality assessed by the ECERS-R across 20 preschools in the USA. Since the Nordic preschool model is characterised by a focus on 'learning through play', outdoor play opportunities and PA are viewed as important aspects of quality (Einarsdottir, 2013). Thus, more research is needed to evaluate the suitability of ECERS-R as applied to a Norwegian context.

The aim of the present study was to examine the relationship between outdoor time and objectively measured MVPA and preschool environmental quality assessed by the ECERS-R in Norwegian preschools. Consistent with previous evidence (Dowda et al., 2009), we hypothesised that outdoor time and levels of MVPA was positively related to general preschool quality. 


\section{K. Fohannessen et al.}

\section{Methods}

Study design and recruitment of participants

The Sogn og Fjordane Preschool Physical Activity Study (PRESPAS) is a large populationbased cross-sectional study conducted in the county of Sogn og Fjordane in Western Norway (Nilsen et al., 2019). This is mainly a rural area with scattered population and nature defined by fjords and mountains. The study was conducted between September 2015 and June 2016, and recruitment of participants was performed in three steps: at the municipality level, at the preschool level, and at the child (parent) level. We invited 15 out of 26 municipalities in the county to participate in the study, of which a subsample of 3 municipalities were selected for the assessment of ECERS-R. The sub-sample was a sample of convenience based on their location in proximity of the University. For the main study, a total of 1925 children aged 2.7-6.5 years were invited from preschools that had at least six children in the appropriate age group (born in 2010, 2011 and/or 2012), constituting $49 \%$ of the total population of preshoolers in Sogn og Fjordane County. In total, 1308 of 1925 invited children (68\%) participated in the PRESPAS study. In the present analysis, we include only the subsample of municipalities $(n=3)$, preschools $(n=20)$, and children $(n=376)$ having preschool quality assessments. While all invited municipalities and preschools accepted participation in these assessments, the response rate for children were $78 \%$ among these services.

Parents of all participating children received oral and written information about the study and provided written consent prior to testing. Children were provided an explanation of the measurements on their level of understanding. The Norwegian Center for Research Data (NSD) approved the study (reference number: 39061).

\section{Procedures}

PA was measured using the ActiGraph GT3X+ accelerometer (ActiGraph, LLC, Pensacola, Florida, USA) over 14 days during three seasons: the autumn of 2015 (September-December), winter of 2016 (January-March), and spring/summer of 2016 (April-June), to capture seasonal variation. Thus, children included in the study had up to 6 weeks of PA monitoring throughout one preschool year. We visited all preschools and explained the measurement procedure to the preschool teachers and the children before the accelerometers were mounted on the children's right hip. Children were instructed to wear the accelerometer at all times for 14 consecutive days, except during water-based activities or while sleeping (at night). After the registration period, the monitors were collected at the preschool. We included all children providing $\geq 3$ preschool days ( $\geq 270$ min of wear time accumulated between 08:30 and 15:30 hours) in the analyses. Accelerometers were initialized with a sampling rate of $30 \mathrm{~Hz}$ and analyzed in 10-second epochs using the Kinesoft software (KineSoft version 3.3.80, Loughborough, UK). Periods of $\geq 20 \mathrm{~min}$ of zero counts were defined as non-wear time (Esliger et al., 2005). We determined MVPA (min/day) by the criterion suggested by 
Evenson et al. (2008) ( $\geq 2296$ counts per minute). Additionally, we reported wear time (min/day) and total PA (average counts per minute) for descriptive purposes.

Outdoor time was logged for each individual child by the preschool teachers every day during the three 14-day accelerometer monitoring periods. The teachers recorded the time when a child arrived in the morning, the time when the child went outdoors and indoors during the day, and the time when the child left the preschool in the afternoon using a standardized log. The mean outdoor time of the 3 monitoring periods is used for the analysis.

Children's sex and age, parental socioeconomic status (SES: based on the highest education level of a child's mother and/or father (upper secondary school, university $<4$ years, university $\geq 4$ years)) were assessed using a questionnaire completed by the child's mother and/or father. Trained test leaders assessed children's body mass and height during preschool hours. Body mass was measured to the nearest $0.1 \mathrm{~kg}$ using an electronic scale (Seca 899, SECA GmbH, Hamburg, Germany), and height was measured to the nearest $0.1 \mathrm{~cm}$ with a portable stadiometer (Seca 217, SECA GmbH, Hamburg, Germany). Body mass index (BMI: $\mathrm{kg} / \mathrm{m}^{2}$ ) was calculated, and children were classified as normal weight (including underweight), overweight, or obese based on the criteria suggested by Cole et al. (2000).

\section{ECERS-R}

We used ECERS-R to assess both structural and process quality of the preschool environments (Harms et al., 2005). Assessments were conducted among 30 departments within 20 preschools in December 2015 and May/June 2016. All four observers performed standardized training and were assessed for $85 \%$ reliability prior to the data collection. All observations were completed from 9:00 am to 12:30 pm, followed by a structured interview of the preschool director or teacher. The ECERS-R assess global quality for children aged $\geq 2.5$ years old, across 43 items, which are structured within seven subscales: 1) space and furniture 2) personal care routines 3) language reasoning, 4) activities 5) interaction, 6) program structure, and 7) parents and preschool teachers. In this study, we used subscales 1-6, but excluded items 9 (Greeting/ Departing) and 11 (Nap/Rest) because these items were not assessable during the observation period, and item 23 (Sand/Water) because these items are not relevant in Norwegian preschools. Some minor adaptions and clarifications of the ECERS-R scale were made to account for the Norwegian preschool context (Bjørnestad, 2016; Bjørnestad, Gulbrandsen, \& Johansson, 2013). Scoring is performed in a standardized manner according to the manual; each item is rated from 1 to 7 (1: inadequate; 3: minimal; 5: good; 7: excellent). As recommended, the observers scored all indicators, even if an indicator was not met, to avoid losing information. The observers were trained in the field until they reached an interrater agreement of at least $85 \%$. In addition, when observers scored wrong indicators for certain items, they were further trained until they could reliably apply these specific indicators (Gordon et al., 2015; Harms et al., 2005). 


\section{K. Fohannessen et al.}

\section{Statistical analysis}

Children's characteristics, PA, and SED were reported as frequencies, means and standard deviations (SD). ECERS scores were reported as means, SDs, and minimum-maximum values. Pearson's correlation coefficients were used to determine interrelationships between ECERS subscales and between MVPA and outdoor time.

Associations for ECERS items and subscales with outdoor time and MVPA were determined using multivariate pattern analysis to handle the whole scale in one joint model taking into account the strong interrelationships between items and subscales. Partial least squares (PLS) regression analyses (Wold et al., 1984) decomposes the explanatory variables into orthogonal linear combinations (PLS components), while simultaneously maximizing the covariance with the outcome variable. Thus, PLS regression can handle completely collinear variables through the use of latent variable modelling (Wold et al., 1984). The multivariate correlations are interpreted similar to bivariate correlations, though they are derived from the multivariate space. Models were validated using Monte Carlo resampling (Kvalheim et al., 2018) with 1000 repetitions by repeatedly and randomly keeping $50 \%$ of the subjects as an external validation set. For each model, we used target projection (Kvalheim \& Karstang, 1989; Rajalahti \& Kvalheim, 2011) followed by reporting of multivariate correlation coefficients with $99 \%$ confidence intervals (CIs) to show the importance of each item and subscale in the multivariate space (Aadland et al., 2019; Rajalahti, Arneberg, Berven, et al., 2009; Rajalahti, Arneberg, Kroksveen et al., 2009). We used conservative CIs $(p=.01)$ to take into account the dependency of observations within preschools as we were not otherwise able to account for the hierarchical structure of the data. To adjust for sources of variation and confounding, we obtained residuals from linear regression models using outdoor time (adjusted for sex, age, and BMI) and MVPA (adjusted for sex, age, BMI, and wear time) as outcomes, prior to performing the multivariate pattern analyses. MVPA was further adjusted for outdoor time in a secondary model. Analyses were performed by means of the commercial software Sirius version 11.0 (Pattern Recognition Systems AS, Bergen, Norway).

\section{Results}

\section{Description of the sample}

Of the 376 children that participated in the study, 374 children performed at least one accelerometer measurement. Of these children, 358 children provided valid data on age, sex, BMI, outdoor time, and accelerometer data, and were included in the analyses (Table 1). Children had a median of 27 valid preschool monitoring days of PA. The majority of children had a normal weight status (84\%) and were born in Norway (98 \%). Boys were more physically active than girls (12\% for overall PA; $21 \%$ for MVPA). Children spent a mean (SD) of 6.7 (0.6) hours/day in preschool, of which 3.0 
(0.5) hours (44\%) were spent outdoors. On a preschool department level, outdoor time varied from 117 to $216 \mathrm{~min} /$ day and MVPA varied from 29 to $57 \mathrm{~min} /$ day.

There was no difference in PA between the children included in these analyses $(\mathrm{n}=358)$ compared to the larger PRESPAS sample $(\mathrm{p} \geq .315)$.

Table 1. Children's characteristics

\begin{tabular}{|c|c|c|c|}
\hline & $\begin{array}{c}\text { Total sample } \\
\mathbf{n}=358\end{array}$ & $\begin{array}{c}\text { Boys } \\
\mathrm{n}=185(52 \%)\end{array}$ & $\begin{array}{c}\text { Girls } \\
\mathrm{n}=173(48 \%)\end{array}$ \\
\hline Age (years) & $4.7(0.9)$ & $4.6(0.9)$ & $4.7(0.9)$ \\
\hline \multicolumn{4}{|l|}{ Ethnicity of child (\%) } \\
\hline Born in Norway & 98 & 97 & 98 \\
\hline Mother born in Norway & 91 & 93 & 90 \\
\hline Father born in Norway & 90 & 91 & 90 \\
\hline Body mass (kg) & $19.0(3.1)$ & $19.2(3.3)$ & $18.8(2.8)$ \\
\hline Height $(\mathrm{cm})$ & $108.2(7.5)$ & $108.5(8.0)$ & $107.9(7.0)$ \\
\hline BMI (kg/m2) & $16.1(1.3)$ & $16.2(1.3)$ & $16.1(1.3)$ \\
\hline \multicolumn{4}{|l|}{ BMI status (\%) } \\
\hline Normal & 84 & 87 & 82 \\
\hline Overweight & 14 & 11 & 16 \\
\hline Obese & 2 & 2 & 2 \\
\hline \multicolumn{4}{|l|}{ Parental education level $(\%)^{\star}$} \\
\hline$\leq$ Upper secondary school & 14 & 12 & 16 \\
\hline University $<4$ years & 27 & 28 & 27 \\
\hline University $\geq 4$ years & 59 & 60 & 57 \\
\hline \multicolumn{4}{|l|}{ Physical activity (preschool) } \\
\hline Wear time (min/day) & $408(10)$ & $408(11)$ & $408(9)$ \\
\hline Overall PA (cpm) & $827(210)$ & $871(240)$ & $780(161)$ \\
\hline MVPA (min/day) & $43(14)$ & $47(15)$ & $39(11)$ \\
\hline \multicolumn{4}{|l|}{ Time use (minutes/day) } \\
\hline Total day & $411(37)$ & $411(35)$ & $411(39)$ \\
\hline Indoor & $230(42)$ & $230(43)$ & $231(41)$ \\
\hline Outdoor & $181(30)$ & $182(31)$ & $181(29)$ \\
\hline
\end{tabular}

All values are mean $\pm \mathrm{SD}$ unless stated otherwise; $\mathrm{SD}=$ standard deviation; $\mathrm{BMI}=$ body mass index. $\mathrm{BMI}$ status defined according to Cole et al. (2000). ${ }^{\star}$ Parental education level: highest level of mother or father $(\mathrm{n}=277)$.

\section{ECERS}

Table 2 shows the ECERS-R subscale ratings and interrelationships among the 30 departments within the 20 preschools. Mean levels were "minimal" to "good" across the subscales but varied from 1.8 to 7.0 among the departments. Scores for "Personal Care Routines", "Language-Reasoning", "Interaction", and "Program Structure" subscales were moderately positive correlated $(r=0.40$ to 0.69$)$. 


\section{K. Johannessen et al.}

Table 2. ECERS subscale scores and interrelationships

\begin{tabular}{|c|c|c|c|c|c|c|c|c|c|}
\hline & \multirow[t]{2}{*}{ Subscale } & & & 2 & 3 & 4 & 5 & 6 & 7 \\
\hline & & Mean (SD) & Min, $\max$ & \multicolumn{6}{|c|}{ Correlation } \\
\hline 1 & Space and Furnishings & $4.8(0.5)$ & $4.0,5.8$ & 0.23 & 0.12 & 0.00 & 0.29 & 0.24 & 0.40 \\
\hline 2 & Personal Care Routines & $4.6(1.2)$ & $1.8,6.4$ & & 0.40 & 0.08 & 0.68 & 0.59 & 0.84 \\
\hline 3 & Language-Reasoning & $4.3(0.7)$ & $2.7,5.5$ & & & 0.34 & 0.69 & 0.64 & 0.76 \\
\hline 4 & Activities & $3.7(0.5)$ & $3.0,4.9$ & & & & 0.22 & 0.14 & 0.33 \\
\hline 5 & Interaction & $5.1(1.2)$ & $3.0,7.0$ & & & & & 0.40 & 0.87 \\
\hline 6 & Program Structure & $5.8(0.8)$ & $3.5,7.0$ & & & & & & 0.74 \\
\hline 7 & Total score & $4.6(0.5)$ & $3.7,5.7$ & & & & & & \\
\hline
\end{tabular}

Scale: 1 = inadequate to $7=$ excellent.

\section{Associations between ECERS-R, outdoor time, and MVPA}

Time spent outdoor and in MVPA were positively associated $(\mathrm{r}=0.19, \mathrm{p}<.001)$. Associations for ECERS items and subscales with outdoor time (51.4\% explained variance, 10 PLS components) and MVPA (5.4\% explained variance, 1 PLS component) are shown in Figures 1 and 2, respectively. All subscales, except "Activities", and the total score were negatively related to time spent outdoors,

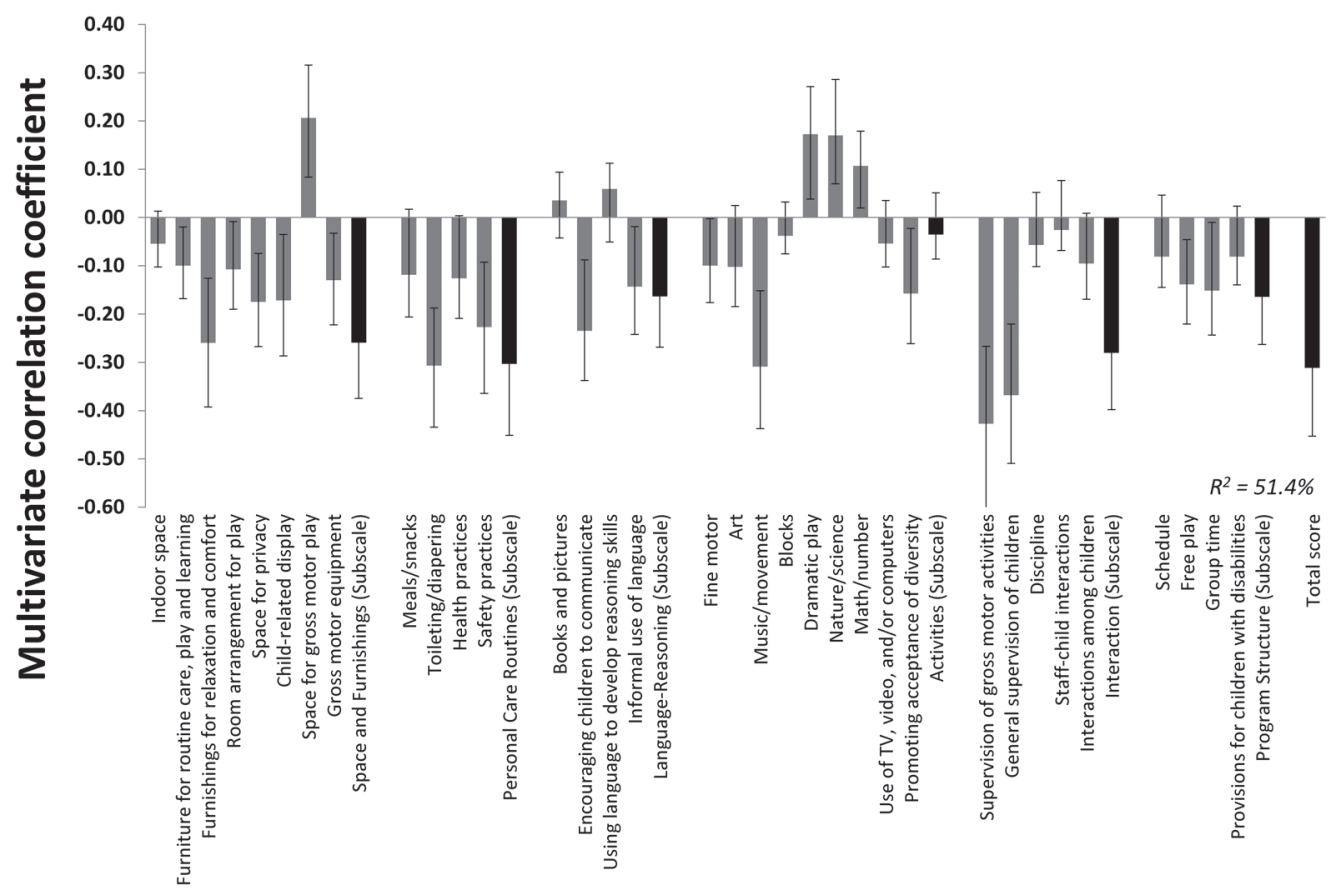

Figure 1. The association between ECERS-R and time spent outdoors. Multivariate correlation coefficients can be interpreted equivalent to bivariate correlations, though they are derived from the multivariate space. 


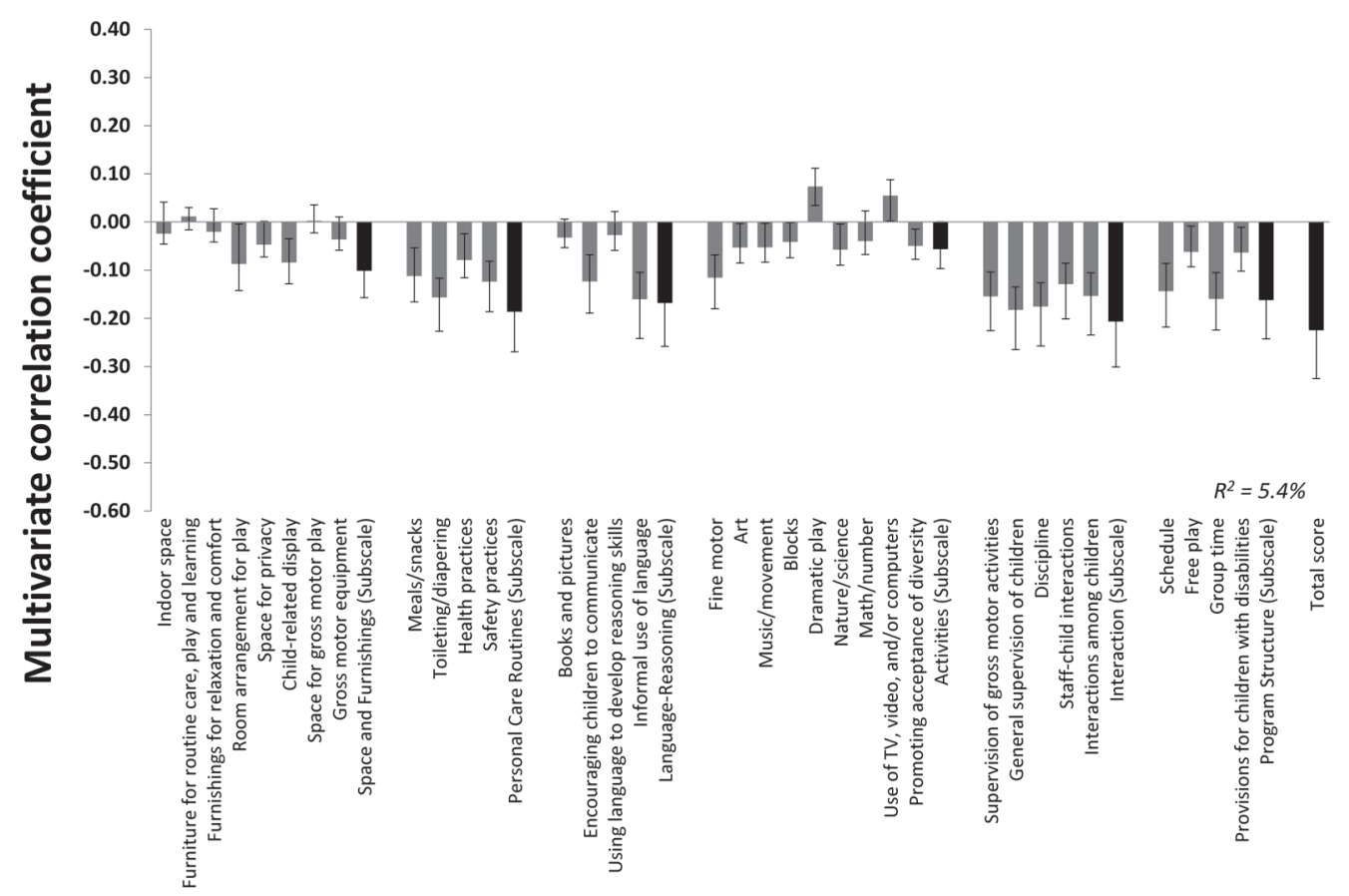

Figure 2. The association between ECERS-R and MVPA. Multivariate correlation coefficients can be interpreted equivalent to bivariate correlations, though they are derived from the multivariate space.

that is, in departments with higher ECERS scores children spent less time outdoors. Associations were strongest for the "Space and Furnishings", "Personal Care Routines", and "Interaction" subscales. The overall strongest associations were found for the "Supervision of gross motor activities" and "General supervision of children" items. Similar to the results for outdoor time, in departments with higher ECERS scores children had lower levels of MVPA. For MVPA, the strongest negative associations were found for "Personal Care Routines", "LanguageReasoning", and "Interaction" subscales. However, associations for MVPA were much weaker than for outdoor time and were completely attenuated when adjusting for time spent outdoors.

\section{Discussion}

The present study examined the associations for preschool environmental quality as measured using the ECERS-R with children's outdoor time and objectively measured PA level. The main finding was a negative association between preschool environmental quality and both outdoor time and MVPA. This finding raises important questions with regard to how preschool environmental quality could be understood, assessed, and improved. As evidence shows PA have broad influences on child development, 


\section{K. Fohannessen et al.}

including learning outcomes (Carson et al., 2017; Timmons et al., 2012), the quality of preschool settings should also include promotion of PA to ensure optimal development during the early years. Preschool children discover the world and learn through movement and play in interaction with their surroundings, which means that abundant movement opportunities should be an integrated part of different learning areas for young children, and thus, an important factor in how we understand high preschool quality.

ECERS-R is one of the most widely used observational tools for assessing the environmental quality of preschool classrooms around the world. The ECERS-R measures different constructs of quality, of which some domains may significantly affect children's opportunities for movement, exploration, and being outdoors. Specifically, furnishing and adequate space, quality of the activities offered, program structure, and interaction among children and among children and teachers, including supervision and safety practices, might promote or restrict children's PA. While Dowda et al. (2004, 2009) reported less SED and more MVPA in preschools that achieved higher scores on ECERS-R, we found a negative association with time spent outdoors and MVPA for the overall score as well as the Space and Furnishings, Personal Care Routines, Language-Reasoning, Interaction and Program Structure subscales. These findings obviously result from how quality of the early years environment is understood and operationalized in the ECERS-R scale, influenced by differences in cultural and pedagogical policies and practices across countries and contexts.

Consistent with previous findings, we found that more outdoor time was associated with more PA (Gray et al., 2015; Hinkley et al., 2008; Stone \& Faulkner, 2014). This finding is probably explained by children's access to large playgrounds with varying topography and portable equipment, inviting children to participate in vigorous play involving running, jumping, etc. Also, norms generally restrict such activities indoors. Furthermore, preschool quality was negatively related to both MVPA and time spent outdoors in the present study. However, since the association between preschool quality and MVPA was attenuated when controlling for time spent outdoors, the association between preschool quality and MVPA can be explained largely by the fact that preschools achieving a higher quality score spent less time outdoors. Thus, the following discussion will target both MVPA and outdoor time to provide an integrated view on how these features may be related to quality.

While US and British childcare policies and objectives are characterized by a high focus on school readiness and thus target curricular achievement to meet this goal (Engel et al., 2015), the Nordic preschool model is largely characterized by a whole-child approach focusing on children's diversity, well-being, free play, tumbling, and exploration. Norwegian preschools are regulated by the The Norwegian Framework Plan for Kindergartens (The Norwegian Directorate for Education and Training, 2017). The framework plan reflects the Nordic socio-pedagogical tradition with a holistic approach to play and learning including a child-oriented pedagogy 
that emphasizes children's well-being, social equality, and active participation (Engel et al., 2015). Importantly, children's free play, PA, and spending time outdoors is also highly valued as the framework plan specifies that children should have abundant opportunities to experience nature and to develop both fine and gross motor skills (The Norwegian Directorate for Education and Training, 2017). Such differences in childcare models between different countries may explain how different quality items are valued, and thus operationalized, in the ECERS-R instrument and in the preschool practice. Our results suggest that preschools that focus more on the indoor learning environment, and achieve a higher quality score, spend less time outdoors and, thus, achieve less MVPA. On the contrary, those that view the outdoor environment more important spend less time indoor, achieve more MVPA, and correspondingly - a lower quality score.

Activities performed outdoors is often dominated by child-initiated free play, without interference from preschool teachers. Thus, given a finite time in-care, time spent outdoors might be viewed as retracting from better-used time spent indoors. This view could be supported by the negative association for the Language-reasoning and Program structure subscales with outdoor time and PA. However, associations were stronger for subscales capturing aspects of the physical environment, personal care and safety practices, suggesting these subscales are the main areas of importance.

The Space and Furnishings subscale capture aspects regarding indoor and outdoor space, furnishings, organization of rooms, and availability of gross motor equipment. To achieve a high ECERS-R score, the environment is organized to promote activities such as, for example, art activities, blocks, dramatic play, reading, nature/ science and manipulatives/fine motor skills. An environment facilitating such activities may not invite children to be physically active (outdoors), but rather lead to more sedentary activities (indoors). Importantly, "Space for gross motor play" (item 7) was positively related to outdoor time, showing that preschools having a large, accessible outdoor area with varied surfaces to support child motor development spent more time outdoors. Many preschools in Western Norway have outdoor areas dominated by relatively large natural environments. This was also the case for the current study sample. Importantly, contact with nature and the ability to move in a rugged natural environment is important, and can contribute the health and well-being of children (Chawla \& Nasar, 2015). However, the provision of opportunities for optimal challenge and development outdoors (associated with higher levels of MVPA), might challenge children's safety and thus require sufficient supervision and good safety practices.

Outdoor pursuits and (risky) free play without strict adult supervision has relatively high tolerance and acceptance in Norway and some other European countries (e.g., Denmark, Sweden, and Italy) (New et al., 2005). Some of the explanation may be that the Norwegian framework plan emphasize children's opportunities for play, exploration, meaningful experiences, and activities in challenging environments 


\section{K. Fohannessen et al.}

(The Norwegian Directorate for Education and Training, 2017). This issue is of relevance to understand our results and the conceptualization and value of vigorous and risky play in relation to safety standards that would restrict such activities (and cause a negative relationship between this ECERS-R item and outdoor time and MVPA).

According to Sandseter (2007) risky play include "thrilling and exciting forms of physical play that involves uncertainty and a risk of physical injury", and includes play with great heights or high speed, play with dangerous tools, play near dangerous elements, rough and tumble play, and play where children can get lost. Such an acceptance of risky play, possibly with restricted supervision, is in conflict with the understanding of quality reflected by ECERS-R. The items "Safety practices" (item 14), "Supervision of gross motor activities" (item 29), and "General supervision of children" (item 30) is rated low if the supervision is inadequate due to a limited number of staff, if teachers are not available to the children, if the communication and interaction between children and adults is poor, if children are not supervised near areas of potential danger, and if younger children (3-4 years of age) play near tall playground equipment without adult supervision (according to the Norwegian adapted version of ECERS-R). In Norway, and especially in the rural area where the present study took place, preschools generally offer large playgrounds and natural areas having hills, trees, rocks, etc., where children can run, jump, climb, hide, and play, including the use of "dangerous" objects, which may be categorized as risky play (Sandseter, 2007). Thus, despite the preschool teachers' awareness of safety, supervision might be difficult at times. Norwegian practitioners evaluate these environments as important for the development of children's motor competence, their learning of new skills, for developing their courage and self-confidence, and for improving their social functioning (Sandseter, 2007; Sandseter et al., 2012). However, allowing much free play on large playgrounds where children have the opportunity to hide, may result in some children achieving limited attention by teachers (Alvestad et al., 2019), which clearly illustrates the challenge of seeing every child's needs (which is evaluated in the ECERS-R). Outdoor time, often scheduled after lunch, is also frequently used for staff breaks, lunch, meetings, or planning, which further challenge the capacity of supervision. Moreover, due to teacher absence during this period, fewer adults, and to a large extent assistants (non-educated staff), are often supervising children during outdoor time, which implies outdoor time is not regarded a period of focused pedagogical content (Gotvassli et al., 2020). To this end, preschools might benefit from reconsideration of their organization for improved child developmental outcomes and safety in line with the aims of the framework plan.

Finally, spending a lot of time outdoors or on field trips, makes it difficult to implement good hygiene and hand wash routines to obtain a high ECERS-R rating (Personal Care subscale). Notably, ECERS-R is an international assessment tool especially adapted to American preschools. Following an increased acceptance of 
outdoor activities in Norway, norms of personal care may also differ, since good hand wash routines and toileting might be difficult outdoors or outside of the preschool area. Even though the Norwegian Institute of Public Health have compiled special routines for hygiene in preschools, there seem to be poor hygiene especially towards handwash in many preschools (Wolf \& Svenning, 2018). Moreover, strong compliance with such routines may further compromise supervision of play activity in a situation of already few teachers available. Given the importance of outdoor time and PA for children's health and development (Carson et al., 2017; Tandon et al., 2018) the issues raised in this paper need attention for improvement of preschool quality and quality assessment. Given the position of outdoor activities in Norwegian preschools, further development of quality assessment tools might be needed to capture relevant characteristics related to quality in the outdoor environment and in a Norwegian context.

Our results showing negative associations between preschool quality and outdoor time may contrast those of Alvestad et al. (2019) who concluded that Norwegian high-quality preschools (measured by ECERS-R) spent much time outdoors. However, Alvestad et al. (2019) did not investigate the association between quality and outdoor time. The finding that preschools had high quality and high outdoor time, might just indicate that outdoor time in Norwegian preschools are high, which is consistent with the finding by Ulset et al. (2017) and our finding, showing children spent 5 and 3 hours/day outdoors, respectively. A similar argument could be made against our points discussed above; that even though values, norms, and quality in Norwegian preschools might differ from other contexts, the negative association between outdoor time/PA and preschool quality found herein does not say anything about the actual level of quality, PA, or outdoor time. However, while Norwegian legislation provide detailed regulations of preschool's structural quality, such as the size of play areas and qualifications of preschool teachers, regulations concerning process quality are less specific (The Norwegian Directorate for Education and Training, 2017). This means practices vary. Our results therefore suggest that children in preschools that accept risky play and exploration, that potentially causes a low safety score, spent more time outdoors and achieved more MVPA. Still, spending more time outdoors inevitably means spending less time inside, increased risk of falling, and poorer hygiene.

\section{Strengths and limitations}

Important strengths of the present study include the repeated monitoring of PA and completion of logs of outdoor time over three seasons in children. Due to the variability of habitual PA across seasons, long-term monitoring of PA (14 days) over several seasons improve reliability of the PA measurements over the use of one monitoring period (Aadland et al., 2020). Similarly, logs of time spent outdoors were completed daily for each child over the same periods, capturing seasonal variation within 


\section{K. Johannessen et al.}

preschools. The moderate sample size is a limitation of the study, and the results are not representative for the population of preschools in Sogn og Fjordane County as a whole. Furthermore, preschools in which the children spend a large amount of the day outdoors might have less opportunities to get a high score on the ECERS-R because the tool is less suited to capture quality aspects in the outdoor environment. Thus, associations between preschool environmental characteristics, outdoor time and MVPA should be addressed in future large-scale studies, possibly including comparative analyses across preschool models and context, and other quality measures more suited for outdoor environments, to improve our understanding of these relationships. Finally, despite the multilevel structure of the dataset, we were not able to take this into account in the PLS analyses. Thus, our results must be interpreted carefully.

\section{Conclusion}

Using ECERS-R, which is one of the most widely used observational tools for assessing the environmental quality of preschool classrooms, we showed that preschool quality was negatively associated with time spent outdoors and time in MVPA. In particular, various aspects of safety practices were negatively associated with outdoor time and MVPA, which suggests that a high focus on safety might restrict children from being physically active. Given the importance of PA for the holistic development of young children, abundant movement opportunities should be an integrated part of early childhood education and care services. Our findings therefore challenge the way we define and measure quality, and the way childcare regulations and practices in some cases may restrict children's outdoor play and movement opportunities.

\section{Author biography}

Kjersti Johannessen is Associate Teaching Professor at the Faculty of Education, Arts and Sports at the Western Norway University of Applied Sciences, Campus Sogndal. She mainly teaches in physical activity, health, and child development in Preschool Teacher Education. Research interests include physical activity in children, implementation of physically active learning methods in preschools, and quality assessment of the childcare setting.

Elisabeth Bjørnestad is Professor at the Department of Early Childhood Education at Oslo Metropolitan University. She has a background as a preschool teacher and her research interests are quality in Early Childhood Education and Care, longitudinal studies, and the transition from Preschool to Primary school. Bjørnestad currently leads the ongoing longitudinal study "Better Provision for Norway's Children from Early Childhood Education and Care through Primary School” [BeProS]. Orcid: https://orcid.org/0000-0003-4406-9969 
Ada Kristine Ofrim Nilsen is Associate Professor at the Faculty of Education, Arts and Sports at the Western Norway University of Applied Sciences, Campus Sogndal. She has a Ph.D. in Sport Sciences from the Norwegian School of Sport Sciences. Ada's research focuses primarily on physical activity in children from the perspective of public health. Her thesis explored physical activity levels in preschoolers and the influence of individual and environmental characteristics on physical activity participation. Ada's teaching experience is in physical activity, health, and child development in Preschool Teacher Education and in Sport Sciences. Orcid: https://orcid. org/0000-0003-0865-7739

Einar Ylvisåker is Associate Teaching Professor the Faculty of Education, Arts and Sports, Western Norway University of Applied Sciences, Campus Sogndal. He teaches bachelor students in human biology and ball games and has a special interest in soccer. Einar's main research interest is physical activity in children and adolescents.

Merete Nornes-Nymark is Assistant Professor at the Faculty of Education, Arts and Sports at the Western Norway University of Applied Sciences, Campus Sogndal. She mainly teaches pedagogy at the Preschool Teacher Education. Research interests include pedagogical leadership, cultural diversity and migration-related challenges, and ethical perspectives related to the learning environment for children in kindergarten.

Mari Engesæter is Assistant Professor at the Faculty of Education, Arts and Sports Western Norway University of Applied Sciences, Campus Sogndal. She teaches in pedagogy at the Preschool Teacher Education. Her field of research is play, toddlers, and the physical environment in kindergartens.

Lillian Pedersen has a Ph.D. in Educational Sciences for Teacher Education from Oslo Metropolitan University and is an Assistant professor at the Faculty of Education, Arts and Sports at the Western Norway University of Applied Sciences (HVL). Her research focuses primarily on children, movement and identity, and her teaching and supervision experiences is related to play, movement, child development and children as citizens on the Preschool Teacher Education and on the Master in Special Education.

Eivind Aadland is Professor and head of the research group Physical Activity and Health at the Faculty of Education, Arts and Sports, Western Norway University of Applied Sciences, Campus Sogndal. His main research interests are in the fields of physical activity, health, and development in children and youth, particularly focusing on the preschool and school contexts, measurement of physical activity by accelerometry, and development of statistical approaches for analyzing physical activity data. He leads several large-scale projects seeking to understand and promote physical 


\section{K. Johannessen et al.}

activity behaviors and concomitant health and developmental outcomes in young children within the Early Childhood Education and Care setting. Orcid: https:// orcid.org/0000-0001-9654-2653

\section{References}

Aadland, E., Andersen, L. B., Resaland, G. K., \& Kvalheim, O. M. (2019). Interpretation of multivariate association patterns between multicollinear physical activity accelerometry data and cardiometabolic health in children - a tutorial. Metabolites, 9(7), 129. https://www.mdpi.com/2218-1989/9/7/129

Aadland, E., Nilsen, A. K. O., Ylvisåker, E., Johannessen, K., Anderssen, S. A., \& Aadland, E. (2020). Reproducibility of objectively measured physical activity: Reconsideration needed. Fournal of Sports Sciences, 1-8. https://doi.org/10.1080/02640414.2020.1743054

Ahn, S., \& Fedewa, A. L. (2011). A meta-analysis of the relationship between children's physical activity and mental health. Fournal of Pediatric Psychology, 36(4), 385-397. https://oi.org/10.1093/jpepsy/jsq107

Alvestad, M., Gjems, L., Myrvang, E., Storli, J., Espedal, T. I. B., Lønning, V. K. \& Bjørnestad, E. (2019). Kvalitet i barnehagen. (Rapport 85, Universitetet i Stavanger). http://hdl.handle.net/11250/2630132

Andersen, L. B., Harro, M., Sardinha, L. B., Froberg, K., Ekelund, U., Brage, S., \& Anderssen, S. A. (2006). Physical activity and clustered cardiovascular risk in children: A cross-sectional study (The European Youth Heart Study). The Lancet, 368(9532), 299-304. https://doi.org/10.1016/S0140-6736(06)69075-2

Belsky, J., Vandell, D. L., Burchinal, M., Clarke-Stewart, K., McCartney, K., \& Owen, M. (2007). Are there long-term effects of early child care? Child Development, 78(2), 681-701. https://doi.org/10.1111/j.14678624.2007.01021.x

Bingham, D. D., Costa, S., Hinkley, T., Shire, K. A., Clemes, S. A., \& Barber, S. E. (2016). Physical activity during the early years: A systematic review of correlates and determinants. American fournal of Preventive Medicine, 51(3), 384-402. https://doi.org/10.1016/j.amepre.2016.04.022

Bjørnestad, E. \& Baustad, A.-G. (2016). Norsk tilpassing og spesifisering av ECERS-R (2015). Høgskolen i Oslo og Akershus (unpublished).

Bjørnestad, E., Gulbrandsen L., Johansson J.-E., \& Os, E. (2013). Metodiske idealkrav og nødvendige tilpasninger. Foreløpig tilstandsrapport fra prosjektet "Better provision for Norway's children in ECEC: A study of children's well-being and Development in ECEC”. Høgskolen i Oslo og Akershus. https://goban.no/files/2013/07/ Metodisk-idealkrav-1.pdf

Bornstein, D. B., Beets, M. W., Byun, W., \& McIver, K. (2011). Accelerometer-derived physical activity levels of preschoolers: A meta-analysis. Fournal of Science and Medicine in Sport, 14(6), 504-511. https://doi. org/10.1016/j.jsams.2011.05.007

Brewer, H. (2018). Foundations of physical activity and health promotion in early childhood. In H. Brewer \& M. R. Jalongo (Eds.), Educating the young child, advances in theory and research, implications for practice; physical activity and health promotion in the early years: Effective strategies for early childhood educators (p. 3-19). Springer.

Brown, W. H., Pfeiffer, K. A., McIver, K. L., Dowda, M., Addy, C. L., \& Pate, R. R. (2009). Social and environmental factors associated with preschoolers' nonsedentary physical activity. Child Development, 80(1), 45-58. https://doi.org/10.1111/j.1467-8624.2008.01245.x

Burchinal, M. (2018). Measuring early care and education quality. Child Development Perspectives, 12(1), 3-9. https://doi.org/10.1111/cdep.12260

Carson, V., Lee, E. Y., Hewitt, L., Jennings, C., Hunter, S., Kuzik, N., Stearns, J. A., Unrau, S. P., Poitras, V. J., Gray, C., Adamo, K. B., Janssen, I., Okely, A. D., Spence, J. C., Timmons, B. W., Sampson, M., \& Tremblay, M. S. (2017). Systematic review of the relationships between physical activity and health indicators in the early years (0-4 years). BMC Public Health, 17(Suppl 5), 854. https://doi.org/10.1186/s12889-017-4860-0

Chawla, L., \& Nasar, J. L. (2015). Benefits of nature contact for children. Fournal of Planning Literature, 30(4), 433-452. https://doi.org/10.1177/0885412215595441

Cole, T. J., Bellizzi, M. C., Flegal, K. M., \& Dietz, W. H. (2000). Establishing a standard definition for child overweight and obesity worldwide: International survey. British Medical fournal, 320(7244), 1240-1243. https://doi.org/10.1136/bmj.320.7244.1240

Cooper, A. R., Goodman, A., Page, A. S., Sherar, L. B., Esliger, D. W., van Sluijs, E. M., Andersen, L. B., Anderssen, S., Cardon, G., Davey, R., Froberg, K. Hallal, P., Janz, K. F., Kordas, K., Kreimler, S. Pate, R. R., Puder, J. J., Reilly, J. J., Salmon. J. ... Ekelund, U. (2015). Objectively measured physical activity and 


\section{Associations for preschool environmental quality with outdoor time}

sedentary time in youth: the International children's accelerometry database (ICAD). International fournal of Behavioral Nutrition and Physical Activity, 12(1), 113. https://doi.org/10.1186/s12966-015-0274-5

Das, P., \& Horton, R. (2016). Physical activity-time to take it seriously and regularly. The Lancet, 388(10051), 1254-1255. https://doi.org/10.1016/S0140-6736(16)31070-4

Dowda, M., Brown, H. W., McIver, K., Pfeiffer, K. A., O Neill, J. R., Addy, C., \& Pate, R. R. (2009). Policies and characteristics of the preschool environment and physical activity of young children. Pediatrics, 123(2), e261-e266. https://doi.org/10.1542/peds.2008-2498

Dowda, M., Pate, R. R., Trost, S. G., Almeida, M., \& Sirard, J. R. (2004). Influences of preschool policies and practices on children's physical activity. Fournal of Community Health, 29(3), 183-196. https://doi. org/10.1023/B:JOHE.0000022025.77294.af

Einarsdottir, J. (2013). Early childhood teacher education in the Nordic countries. European Early Childhood Education Research fournal, 21(3), 307-310. https://doi.org/10.1080/1350293X.2013.814321,

Engel, A., Barnett, S., Anders, Y., \& Taguma, M. (2015). Early childhood education and care policy review Norway. Organisation for Economic Co-operation and Development. http://www.oecd.org/norway/early-childhoodeducation-and-care-policy-review-norway.pdf

Esliger, D. W., Copeland, J. L., Barnes, J. D., \& Tremblay, M. S. (2005). Standardizing and optimizing the use of accelerometer data for free-living physical activity monitoring. Fournal of Physical Activity and Health, 2(3), 366-383. https://doi.org/10.1123/jpah.2.3.366

European Commission. (2009). The provision of childcare services: A comparative review of 30 European countries. https://www.fruehe-chancen.de/fileadmin/PDF/Archiv/the_provision_childcare_services.pdf

Evenson, K. R., Catellier, D. J., Gill, K., Ondrak, K. S., \& McMurray, R. G. (2008). Calibration of two objective measures of physical activity for children. Fournal of sports sciences, 26(14), 1557-1565. https:// doi.org/10.1080/02640410802334196

Finn, K., Johannsen, N., \& Specker, B. (2002). Factors associated with physical activity in preschool children. fournal of Pediatrics, $140(1), 81-85$. https://doi.org/10.1067/mpd.2002.120693

Goldfield, G., Harvey, A., Grattan, K., \& Adamo, K. (2012). Physical activity promotion in the preschool years: A critical period to intervene. International fournal of Environmental Research and Public Health, 9(4), 1326-1342. https://doi.org/10.3390/ijerph9041326

Gordon, R. A., Hofer, K. G., Fujimoto, K. A., Risk, N., Kaestner, R., \& Korenman, S. (2015). Identifying high-quality preschool programs: New evidence on the validity of the early childhood environment rating scale-revised (ECERS-R) in relation to school readiness goals. Early Education and Development, 26(8), 1-25. https://doi.org/10.1080/10409289.2015.1036348

Gotvassli, K.-Å., Haugset, A. S., \& Ljunggren, B. (2020). Kvalitet og didaktisk arbeid i barnehagen. In K.-Å. Gotvassli (Ed.), Kvalitetsutvikling $i$ barnehagen. Fra vurdering til ny pedagogisk praksis. (p. 76-102). Universitetsforlaget.

Gray, C., Gibbons, R., Larouche, R., Sandseter, E., Bienenstock, A., Brussoni, M., Chabot, G., Herrington, S., Janssen, I., Pickett, W., Power, M., Stanger, N., Sampson, M., \& Tremblay, M. (2015). What is the relationship between outdoor time and physical activity, sedentary behaviour, and physical fitness in children? A systematic review. International fournal of Environmental Research and Public Health, 12(6), 6455-6474. https://doi.org/10.3390/ijerph120606455

Harms, T., Clifford, R., \& Cryer, D. (2005). Early childhood environment rating scale (Rev. ed.). Teacher College Press.

Hesketh, K. R., O’Malley, C., Paes, V. M., Moore, H., Summerbell, C., Ong, K. K., Lakshman, R., \& van Sluijs, E. M. F. (2017). Determinants of change in physical activity in children 0-6 years of age: A systematic review of quantitative literature. Sports medicine, 47(7), 1349-1374. https://doi.org/10.1007/s40279-0160656-0

Hinkley, T., Crawford, D., Salmon, J., Okely, A. D., \& Hesketh, K. (2008). Preschool children and physical activity - A review of correlates. American fournal of Preventive Medicine, 34(5), 435-441. https://doi. org/10.1016/j.amepre.2008.02.001

Hinkley, T., Salmon, J., Crawford, D., Okely, A., \& Hesketh, K. (2016). Preschool and childcare center characteristics associated with childrens physical activity during care hours: An observational study. International fournal of Behavioral Nutrition and Physical Activity, 13(1), 117. https:/doi.org/10.1186/ s12966-016-0444-0

Hinkley, T., Salmon, J., Okely, A. D., Hesketh, K., \& Crawford, D. (2012). Correlates of preschool children's physical activity. American fournal of Preventive Medicine, 43(2), 159-167. https://doi.org/10.1016/ j.amepre.2012.04.020 


\section{K. Johannessen et al.}

Kvalheim, O. M., Arneberg, R., Grung, B., \& Rajalahti, T. (2018). Determination of optimum number of components in partial least squares regression from distributions of the root-mean-squared error obtained by Monte Carlo resampling. Fournal of Chemometrics, 32(4). https://doi.org/10.1002/cem.2993

Kvalheim, O. M., \& Karstang, T.V. (1989). Interpretation of latent variable regression models. Chemometrics and Intelligent Laboratory Systems, 7(1-2), 39-51. https://doi.org/10.1016/0169-7439(89)80110-8

Malina, R. M. (2001). Physical activity and fitness: Pathways from childhood to adulthood. American fournal of Human Biology, 13(2), 162-172. https:/doi.org/10.1002/1520-6300(200102/03)13:2

Mashburn, A. J., Pianta, R. C., Hamre, B. K., Downer, J.T., Barbarin, O. A., Bryant, D., Burchinal, M., Early, D. M., \& Howes, C. (2008). Measures of classroom quality in prekindergarten and children's development of academic, language, and social skills. Child Development, 79(3), 732-749. https://doi.org/10.1111/j.14678624.2008.01154.x

New, R. S., Mardell, B., \& Robinson, D. (2005). Early childhood education as risky business: Going beyond what's "safe" to discovering what's possible. Early Childhood Research and Practice, 7(2), 1-21. https://files. eric.ed.gov/fulltext/EJ1084843.pdf

Nilsen, A. K. O., Anderssen, S. A., Ylvisaaker, E., Johannessen, K., \& Aadland, E. (2019). Physical activity among Norwegian preschoolers varies by sex, age, and season. Scandinavian fournal of Medicine and Science in Sports, 29(6), 862-873. https://doi.org/10.1111/sms.13405

Rajalahti, T., Arneberg, R., Berven, F. S., Myhr, K. M., Ulvik, R. J., \& Kvalheim, O. M. (2009). Biomarker discovery in mass spectral profiles by means of selectivity ratio plot. Chemometrics and Intelligent Laboratory Systems, 95(1), 35-48. https://doi.org/10.1016/j.chemolab.2008.08.004

Rajalahti, T., Arneberg, R., Kroksveen, A. C., Berle, M., Myhr, K. M., \& Kvalheim, O. M. (2009). Discriminating variable test and selectivity ratio plot: Quantitative tools for interpretation and variable (biomarker) selection in complex spectral or chromatographic profiles. Analytical Chemistry, 81(7), 2581-2590. https:// doi.org/10.1021/ac802514y

Rajalahti, T., \& Kvalheim, O. M. (2011). Multivariate data analysis in pharmaceutics: A tutorial review. International Fournal of Pharmaceutics, 417(1-2), 280-290. https://doi.org/10.1016/j.ijpharm.2011.02.019

Sandseter, E. B. H. (2007). Categorising risky play - how can we identify risk-taking in children's play? European Early Childhood Education Research fournal, 15(2), 237-252. https://doi.org/10.1080/13502930701321733

Sandseter, E. B. H., Little, H., \& Wyver, S. (2012). Do theory and pedagogy have an impact on provisions for outdoor learning? A comparison of approaches in Australia and Norway. Fournal of Adventure Education and Outdoor Learning, 12(3), 167-182. https://doi.org/10.1080/14729679.2012.699800

Statistics Norway. (2017). Number of children in Kindergartens. https://www.ssb.no/en/utdanning/statistikker/ barnehager

Stone, M.R., \& Faulkner, G.E.J. (2014). Outdoor play in children:Associations with objectively-measured physical activity, sedentary behavior and weight status. Preventive Medicine, 65, 122-127. https://doi.org/10.1016/ j.ypmed.2014.05.008

Tandon, P. S., Saelens, B. E., Zhou, C., Christakis, D. A., \& Tandon, P. S. (2018). A comparison of preschoolers' physical activity indoors versus outdoors at child care. International fournal of Environmental Research and Public Health, 15(11), 2463. https://doi.org/10.3390/ijerph15112463

Tetens, I., Pedersen, A. N., Schwab, U., Fogelholm, M., Thorsdottir, I., Gunnarsdottir, I., ... Wirfält, E. (2012). Nordic nutrition recommendations 2012: Integrating nutrition and physical activity. (Nordisk råd report 2014:002). https://www.norden.org/no/node/7832

The Norwegian Directorate for Education and Training. (2017). Framework plan for Kindergartens. https://www. udir.no/globalassets/filer/barnehage/rammeplan/rammeplan-for-barnehagen-bokmal 2017.pdf

Timmons, B. W., LeBlanc, A. G., Carson, V., Gorber, S. C., Dillman, C., Janssen, I., Kho, M. E., Spence, J., Stearns, A., \& Tremblay, M. S. (2012). Systematic review of physical activity and health in the early years (aged 0-4 years). Applied Physiology Nutrition and Metabolism, 37(4), 773-792. https://doi.org/10.1139/ h2012-070

Tonge, K. L., Jones, R. A., \& Okely, A. D. (2016). Correlates of children's objectively measured physical activity and sedentary behavior in early childhood education and care services: A systematic review. Preventive Medicine, 89, 129-139. https://doi.org/10.1016/j.ypmed.2016.05.019

Trost, G. S., Ward, S. D., \& Senso, S. M. (2010). Effects of child care policy and environment on physical activity. Medicine E Science in Sports E Exercise, 42(3), 520-525. https:/doi.org/10.1249/MSS.0b013e3181cea3ef

Truelove, S., Bruijns, B. A., Vanderloo, L. M., Brien, K. T., Johnson, A. M., \& Tucker, P. (2018). Physical activity and sedentary time during childcare outdoor play sessions: A systematic review and meta-analysis. Preventive Medicine, 108, 74-85. https://doi.org/10.1016/j.ypmed.2017.12.022 
Ulset, V., Vitaro, F., Brendgen, M., Bekkhus, M., \& Borge, A. I. H. (2017). Time spent outdoors during preschool: Links with children's cognitive and behavioral development. Fournal of Environmental Psychology, 52, 69-80. https://doi.org/10.1016/j.jenvp.2017.05.007

Vanderloo, L. M., Tucker, P., Johnson, A. M., Burke, S. M., \& Irwin, J. D. (2015). Environmental influences on preschoolers' physical activity levels in various early-learning facilities. Research Quarterly for Exercise and Sport, 86(4), 1-11. https://doi.org/10.1080/02701367.2015.1053105

WHO. (2019). Guidelines on physical activity, sedentary behaviour and sleep for children under 5 years of age. From https://apps.who.int/iris/handle/10665/311664.

Wold, S., Ruhe, A., Wold, H., \& Dunn, W. J. (1984). The colinearity problem in linear regression - the partial least squares (PLS) approach to generalized inverses. Siam fournal on Scientific and Statistical Computing, 5(3), 735-743. https://doi.org/10.1137/0905052

Wolf, K. R. D., \& Svenning, S. B. (2018). Perspektiver på barns medvirkning i barnehagen. Universitetsforlaget. 